\title{
The Economic Effect of Trademarks
}

\section{A.G.Papandreou*}

The primary objective of this paper is the description and evaluation of the economic effects of the use of trade-marks in an economy such as ours. The topic is challenging, but its very nature makes it difficult to do much more than put forth a set of speculations which defy an ultimate empirical test. The only argument in support of the thesis I shall expound is this: the thesis follows in a straight-forward fashion from the main tenets of economic doctrine, at least some aspects of which may be considered testable or verifiable.

Much depends, of course, on what we shall choose to inean by "trademark." If we choose to consider it merely as a sign or symbol which identifies the origin of a product or service, the whole issue would become exceedingly uninteresting to an economist. It is clear, however, that simulation of a trade-mark involves more than misrepresentation. It also involves misappropriation. It is misappropriation which gives the clue to the appropriate meaning of the term "trade-mark" so far as the economist is concerned. What is the nature of the misappropriated property? What is its economic origin, and what are the effects of the process through which it is acquired? These are the questions that make the issue important from the point of view of the economist.

As a sign or symbol a trade-mark is necessarily an element of a process of communication, a commumication which typically originates with the owner or seller of a product and which is received by a prospective buyer of that product. A trade-mark always conveys some information. Generally, however, it does much more than that. It suggests, influences, persuades. This distinction between the conveying of information and the exertion of influence is of the essence. Needless to say, however, it is rather elusive. I shall attempt to make that distinction as best I can, in order to be able to draw some inferences which are rather crucial to iny argument. We shall say that a communication conveys information if, and only if, it contains some declarative sentences with respect to which the following two propositions may be asserted: (a) There exist socially accepted rules for establishing their truth or their degree of confirmation given some body of evidence. (b) The truth or degree of confirmation of these declarative sentences is independent of the state of mind of the recipient of the communication. An example might help. If a communication contains the declarative sentence "object X is five feet long" it meets the proposed criterion and may be said to convey imformation. In contrast, the sentence

\footnotetext{
* Professor of Economics, University of California, Berkeley.
} 
"object X tastes good" fails to pass the test. It fails on either or both counts. Even if there exists some socially acceptable rule for establishing the meaning of "tastes good," it is unlikely that the sentence would be true for all possible recipients of the communication. Clearly, the state of mind of the recipient of the communication has soniething to do with its truth.

Typically a trade-mark is an element of a class of communications originating with a seller and relating to sone object. It almost never functions alone. I should like to propose that the class of communications of which the trade-nuark is an element should be called informative, if the choice of a recipient is affected by it exclusively by reason of the fact that it conveyed information. On the other hand, if the choice of the recipient is affected not by the informational content of the communication, but by other aspects of it, then the class of communications should be called infuential. Naturally, the communication may be ineffective, in the sense that it is neither informative nor influential.

This makes it possible for us to distinguish between informative, influential and ineffective uses of trade-niarks, depending on whether or not the class of comnunications of which the trade-mark is a part is informative, influential, or ineffective. I should like to argue that the concept of misappropriation becomes significant primarily in so far as the use of a simulated trade-mark has been influential. A trade-mark is property, so to say, primarily in so far as it represents command or control over the actions of prospective buyers. By definition, therefore, a trade-mark is valuable primarily to the extent that it carries with it some degree of monopoly power.

Economists have put forth a wide variety of definitions of monopoly power. All of them, so far as I know, have this in common: the power to affect the choice or decision of the buyer. The essence of this power is the asymmetrical character of the seller-buyer relationship. The seller, if he has monopoly power, sets his price in full view of the anticipated reaction of the buyer to the set price. The capacity of the seller to set higher alternative prices without losing all his customers to competitors is the evidence of his monopoly power. In view of this concept of monopoly power, it follows that to argue that a trade-mark has been put to influential use is tantamount to arguing that it has given rise to nonopoly power. It should be made clear, of course, that the sources of monopoly power are many and varied. It is merely asserted that influential communications in the form of advertising and other promotional activities, and by implication the influential use of trade-marks, constitute $a$ source of monopoly power.

It should be clear, of course, that the influential use of trade-marks is limited to a certain type of market-namely a market in which the buyers lack expertness. In producers' goods markets advertising and the asociated 
use of trade-marks tend to be of the informative character. The buyers in such markets are business firms. It is unlikely that firms as buyers will exhibit the same degree of inexpertness or misinformation typically exhibited by consumers in a wide variety of markets. The consumers are not equally mexpert in all the markets in which they buy. They can judge meat or vegetables or even clothes a lot better than they can judge an automobile or a lens or a chemical compound. In markets in which the consumers tend to be experts, the use of trade-marks will tend to be either informative or ineffective-but not influential. The misappropriation aspect of trademark simulation, therefore, is particularly if not exclusively relevant for products sold in markets of inexpert consumers. Under these circumstances the support extended by law to trade-marks becomes a support not only of monopóly power but also of a state of inexpertness and misinformation.

It has been argued so far that the influential use of trade-marks brings about or contributes to monopoly power, and that it feeds on and enhances a state of misinformation and inexpertness of the buyer. To be sure, the terms "monopoly power," "mismformation," "inexpertness" are all loaded words. They are loaded in the sense that their use in every day discourse does more than to convey information; it influences; it creates a state of mind or attitude toward the practice in question. The economist would be guilty of "influential" use of the term, if he assumed that monopoly is bad because it is monopoly. Typically economists agree that monopoly power is detrimental to the efficient and equitable functioning of an economic system. This value judgment, however, is asserted not as a self-evident truth, but rather as a theorem derived from a set of axioms which incorporate the typical economist's value commitments. A systematic development of these ideas is impossible here. A brief sketch, however, seems to be in order.

The sketcli to be presented immediately relates to the criterion of Pareto-optimality. In one form or another it underlies most of the value judgments of the professional economist. According to this criterion some state-of-the-world $X$ is superior (or preferable) to some other state-of-theworld $Y$, if at least some one individual is better off in $X$ than in $Y$, and no individual is worse off in $\mathrm{X}$ than in $\mathrm{Y}$. A situation $\mathrm{X}$ will be called optimal if no shift away from it is capable of making some one better off without at the same time making some one worse off. It can be established that a plurality of such Pareto-optimal situations is possible. Two optimal situations are not comparable by definition. It is clear that a shift from one optimal situation to another would make some one better off while at the same time it would make some one worse off. Furthermore, it can be shown that given some particular situation which is not optimal, only a sub-class of all the optimal situations can be said to be superior to it. In other words 
this criterion leads to partial rather than to a complete ordering of the states of the world. It must be stressed here that the unwillingness of the economist to make all situations comparable is a reflection of his individualist orientation. In order to make all situations comparable, he would have to commit himself to an operation whereby somebody's loss would be equated from the social point of view to somebody else's gain. The use of this criterion also reflects the economist's emphasis on efficiency. If it is possible to make someone better off without at the same time making someone else worse off, then it is clear that the state of the world in question is "wasteful." According to the criterion, however, such situations of statesof-the-world are non-optimal, and are, therefore, less desirable than some corresponding optimal situations in which the "waste" has been eliminated. In view of the fact that economists grew and matured in an era and in a culture in which rationalism and individualism were prepotent value orientations, it is not surprising that the criterion more or less generally adopted by economists conforms both to rationalism and to individualism.

Employing this rather weak tool the economist can deduce a set of necessary conditions for an optimum. The conditions are necessary in the sense that they are satisfied, if the situation is an optimum. (It does not follow, however, that their satisfaction guarantees an optimum). One of these necessary conditions is that the marginal or incremental cost of the output produced by a firm must be equal to the product's price in the market. The economist can show, in other words, that if the state of the world is optimal, marginal costs are equal to prices. It can also be shown that typically monopoly power implies a divergence of marginal cost from price, the divergence becoming greater with increases in monopoly power. It follows that if the situation is optimal it cannot lead to the typical outcome in a monopolistic situation. It also follows that given some monopolistic situation a reorganization is possible whereby some one can be made better off without at the sanie time making anybody worse off (including the monopolist). The conclusion is easily reached, then, that the presence of monopoly power implies inefficiency or waste.

In the case of trade-marks the argument cannot rest here. We must face up to the fact that the influential use of trade-marks not only feeds on and enhances the inexpertness of the buyer, but furthermore that resources, scarce productive agents, are being employed to bring about this result. If one were to argue that advertising and the influential use of trade-marks alters people's tastes, whatever this may be taken to mean, we would be very hard put to employ the criterion of optimality presented above. Use of the criterion assumes given tastes. It is somewhat neater, therefore, to think of advertising and promotional activities as affecting buyer behavior in the following manner. They may be informative, in which case they 
affect the buyer's state of information. In this case the communication from seller to buyer makes it possible for the buyer to solve his decision problem in a more satisfactory nanner. Such communications, therefore, improve the status of the buyer. This does not imply, however, that the most efficient way of conveying information to the buyer is through the promotional activities of the sellers. Information is itself a product in whose production resources are utilized. It is interesting to note that in our kind of economic organization information concerning some product is distributed by the seller to all comers, both buyers and non-buyers of the product in question, but is paid for by the buyers of the product. This is tantamount to saying that there is no independent market for information. It follows that it is rather difficult, if not impossible, to evaluate the extent to which the utilization of resources in the advertising or information industry is efficient or not. It seems to me that much can be said in favor of a separation of the function of producing a commodity from the function of producing and selling the relevant information concerning this product. All these remarks were predicated on the assuniption that the communication associated with the advertising or promotional activities was informative. If, instead, it is influential, then it becomes possible to make a much stronger statement to the effect that the resources employed in the provision of this influence are wasted.

This, in general, is the argument that the economist would put forth in connection with the effects of influential uses of trade-marks and similar devices. It might be readily pointed out, however, that the argument is rather rarified, that in this form it is of rather hittle use to the policy maker, to the legislators or the courts concerned with the enactment and enforcement of rules relating to economic behavior. The antitrust or unfair competition legal expert would be hard put to make any use of this analysis in the fornulation of a concept of public policy. He would readily point out that monopoly, in the sense in which the econonnist uses the term, is here to stay; that the provision of information by the seller of a product or the influential use of trade-marks are permanent features of our social and economic organization. He might further assert that, if all the economist can do is to propose some utopian alternative scheme, he will have to formulate policy without consulting him. I propose to deal with this issue in the balance of my paper.

It can be safely asserted that our antitrust policy in the United States has little direct, immediate relation to the criterion of Pareto-optimality. If there is a unifying underlying theme to this body of law, he shall have to search for it on the level of conduct rather than on the level of perform ance. In attributing a unifying theme to our antitrust law we run into the danger of attributing a consistency to it which it does not possess. Admit- 
ting this danger, and freely recognizing that our antitrust policy and law is fraught with inconsistencies, it may still be possible to talk about a predominant theme in the law. All references to the antitrust law in this discussion are, in fact, references to this presumed dominant theme.

It may not be far afield to assert that this dominant theme has to do with the maintenance of the competitive process, with the maintenance of competitive threat or competitive pressure in our economy. Typically (but not exclusively) the evidence for the presence of competitive pressure is sought not in structure or performance, but rather in the prevailing patterns of conduct. Certain patterns of conduct are assumed to generate "high" competitive pressure and lead to an "active" competitive process, whereas others are assumed to generate "low" competitive pressure and to lead, therefore, to a dampened or "muffled" competitive process. In general, the public authority (in the context of the antitrust law) may be said to prefer the "high" competitive pressure to the "low" competitive pressure patterns of conduct. Characteristically the antitrust law as legislated by Congress and interpreted by the courts seems to be aimed at inhibiting the adoption of patterns of conduct which generate "low" competitive pressure. To be exact, the law seems to require that firms do not engage in the following patterns or types of practices: (1) cooperative practices in the market place; (2) coercive, aggressive, or repressive practices which are aimed at the elimination of competitors; (3) restrictive practices which are systematically aimed at reducing the ease with which competitors may enter or obtain access to their market.

It seems to me that the influential use of trade-marks, and the associated class of advertising and promotional activities falls primarily within the domain of the third class of practices. In other words, the influential use of trade-marks is relevant from the point of view of antitrust primarily in its role as a device inhibiting entry and access. The crucial concept here is that of freedom of entry. The essence of the concept of free entry is the absence of differential advantage for the firms already in the market. In fact, the following defimition can be proposed: Entry is free if, and only if, a firm (whether established or not) can enter a market on terms which are at least as favorable as those which are available to the firms already in the market. Entry may be more or less restricted (i.e., may be less or more free) for a variety of reasons: There may be outright legal restrictions on entry. The terms on which outlets for the product, or the terms on which factors of production, or the terms on which technologies and "know-how" are made available may be adversely different for newcomers. Last but not least, the presence of irrational consumer allegiances may constitute an effective barier to entry. Consumer allegiances built over the years with intensive advertising, trade-marks, trade names, copyrights and so forth 
extend substantial protection to firms already in the market. In some markets this barrier to entry may be insuperable.

It may not be amiss to state at this juncture that an intimate relationship exists between the concept of freedom of entry, as defined here, and the concept of monopoly power. Restriction of entry is the fundamental source of monopoly power. To say that a seller exercises some power over his customers because, for instance, they have a strong allegience to his trademark, is to say that no other seller has access to those customers on terms equal to his. Restriction of entry, therefore, is the heart of our problem. It follows, therefore, that the main tenets of our antitrust law have an intimate though indirect connection with the concept of optimality which was discussed earlier in this paper.

If these remarks are valid, it can be argued that section 2 of the Sherman Act ${ }^{1}$ could easily be extended by the courts to advertising and promotional activities. I subnrit, in fact, that this extension would be no different than the extension of the concept of "monopolizing" which was proposed by Judge Learned Hand in the $1945 A l c o a^{2}$ case. It is possible to claim, of course, that section 2 of the Sherman Act, even as interpreted by Judge Learned Hand, does not go far enough. After all the section becomes operative when a firm approaches the status of monopoly (in the legal sense of the word). One night propose, instead, that the phrasing of the AntiMerger Act of $1950^{3}$ nnght be more fitting. I am referring, of course, to the phrase "to substantially lessen competition." Such an interpretation would make it possible to declare unlawful the influential use of trademarks and the associated promotional activities where the effect of such use or activities is to substantially lessen competition.

I have no doubt that such a proposal would meet with very httle sympathy on the part of the legal profession. This is the case, I believe, for two related reasons. To begin with, advertising, promotional activities, and the influential use of trade-marks are part and parcel of our culture-one could say that they are the distinctive mark of our culture. Secondly, legal experts have always viewed trade-marks primarily in the setting of the law of unfair competition rather than that of the antitrust law. It is hardly necessary to point out that much of our law on unfair competition rests on value premises which in part at least contradict those inherent in our antitrust law. In a very real sense the provisions of the law of unfair competi-

126 STAT. 210 (1890), 15 U.S.C. § 2 (1952).

2 United States v. Aluminum Co. of America, 148 F.2d 416 (2d Cir. 1945). After trial in the district court this case was taken on appeal to the Suprene Court where it was placed on a special calendar to be held until a quorum could be obtained. A special statute was subsequently passed allowing the Circuit Court of Appeals for the Second Circuit to decide the case in lieu of the Supreme Court. 58 STAT. 272 (1944), 15 U.S.C. $\$ 29$ (1952).

364 STAT. 1125 (1950), 15 U.S.C. §§ 18, 21 (1952). 
tion aim at extending protection to a firm from the competition of other firms, whereas the provisions of the antitrust law aim at enhancing the threat from competitors. Needless to say, some sort of modus vivendi for these rather contradictory concepts has been achieved. To what extent this modus vivendi would be disturbed by an extension of the provisions of the antitrust law (in the sense discussed above) to the influential use of trademarks must remain a matter of speculation.

If this kind of proposal be considered impractical and adverse to our institutions, an alternative or complementary proposal may be put forth. The public authority may assume the responsibility of insuring that the information appropriate to the making of buying decisions on the part of the public be made available to the public. The discussion of the manner in which this could be accomplished lies beyond the scope of this paper. This much can be said, however. The value of trade-marks will vary inversely with the effectiveness of such an information dissemination program. 